\title{
Germanica
}

\section{Die ermordete Operette}

\section{Eva Philippoff}

\section{(2) OpenEdition}

\section{Journals}

Édition électronique

URL : http://journals.openedition.org/germanica/1533

DOI : 10.4000/germanica. 1533

ISSN : 2107-0784

Éditeur

Université de Lille

\section{Édition imprimée}

Date de publication : 30 juin 2005

Pagination : 197-202

ISBN : 9782913857155

ISSN : 0984-2632

\section{Référence électronique}

Eva Philippoff, «Die ermordete Operette », Germanica [En ligne], 36 | 2005, mis en ligne le 13 juillet 2012, consulté le 06 octobre 2020. URL : http://journals.openedition.org/germanica/1533 ; DOI : https://doi.org/10.4000/germanica.1533

Ce document a été généré automatiquement le 6 octobre 2020.

(c) Tous droits réservés 


\section{Die ermordete Operette}

\section{Eva Philippoff}

Bondy : Warum so kurz, mein Fräulein ? Rosemarie : Weil - Sie dürfen mich aber nicht auslachen; ich habe nämlich einen kleinen Geburtsfehler. Vielleicht haben Sie es schon bemerkt. Ich lisple. Bondy : Gott, wie süss ! Wie mich das freut ! Ich habe nämlich auch einen kleinen Geburtsfehler. (Vielleicht haben Sie es auch schon bemerkt.) Ich bin nämlich ein little... Rosemarie : Little ?

Bondy : Ein Irsraelittle - (Beide lachen) ${ }^{1}$. In New York, wo man so leicht allein sein kann, setzte ich mir, wenn mich die Bitterkeit überkam, auf der Strasse meine dunkle Brille auf, hinter der mich niemand sehen konnte, und weinte ; still, ohne das Gesicht zu verziehen. Ich habe es

gelernt... ${ }^{2}$

1 Es ist bekannt, dass Hitler die Operette liebte - besonders die Lustige Witwe - er liess sich einmal zum Geburtstag ein Programmheft der 50. Aufführung aus dem Jahre 1906 mit eigenhändiger Widmung von Franz Lehàr schenken, auf dessen Titelblatt der jüdische Hauptdarsteller Louis Treumann abgebildet war. Dazu passt auch, dass die Nazis im Matrikelbuch der Pfarre St. Stefan die Eintragung über Johann Strauss'Urgrossvater tilgten, der ein getaufter Jude war. Auch Jan Kiepura, dem strahlenden Operettentenor, wurde sein jüdisches Elternteil in den ersten Zeiten vergeben, damit man im Genuss seiner Stimme bleiben konnte. Leider musste man aber trotz dieser Bemühungen sehr weitgehend auf die Operette verzichten, da der Grossteil ihrer Komponisten und Textdichter sowie Interpreten als Juden verteufelt, verboten und vertrieben wurden, vernichtet und inzwischen der Vergessenheit anheimgefallen sind. 
2 Im Katalog einer Ausstellung über die Operette in Wien im Jahre $1985^{3}$ ist keine Erwähnung davon, dass die Operette und leichte Muse Wiens 1938 radikal ausgerottet wurde. Die Emigration wird in zwei Zeilen abgetan und nur bei solchen Komponisten erwähnt, die relativ glimpflich davongekomen sind, wie Emmerich Kalmàn, Oscar Straus und Robert Stolz, der als Nichtjude aus Überzeugungsgründen nach Frankreich ging. Kein Wort über das tragische Schicksal von Komponisten wie Ralph Benatzky, Paul Abraham, Richard Fall, von Textdichtern wie Julius Brammer, Fritz Grünwald, Fritz Löhner-Beda, oder Interpreten wie Louis Treumann, Richard Tauber, Josef Schmidt, den Wiener Publikumslieblingen Hermann Leopoldi und Karl Farkas. Es musste die wunderbare Ausstellung der Sammlung Dachs mit dem sprechenden Titel «Sag beim Abschied leise Servus... » im Jahre 1992 kommen, um den Finger auf den wunden Punkt zu legen, wie ja überhaupt vor den neunziger Jahren in Österreich kaum mit der Aufarbeitung der Vergangenheit begonnen wurde.

3 Wenn Hitler die Operette liebte, so waren alle in der leichten Muse Tätigen - ob Altösterreicher aus Böhmen, Mähren oder Ungarn, oder in Wien geboren leidenschaftlich in Wien verliebt, und so mancher wünschte sich sogar noch trotz Vertreibung und Exil, in Wien begraben zu sein. Aber es half ihnen nichts ! Sie mussten alle weg, verboten, verfolgt und verdrängt. So beliebt ihre Melodien auch gewesen sein mochten, die Texte der fast durchwegs « nicht-arischen » Künstler wurden plötzlich als dem «deutschen Geist nicht entsprechend", als "Gedusel und Geschmuse », als «musikalischer Saustall» ausgegrenzt und abgeschafft. Sogar die Werkelmänner wurden angezeigt, wenn sie nach März 1938 Melodien von jüdischen Komponisten spielten !

Das Ende einer Kunstperiode, die es vielleicht verdiente, dass man sich Ihrer erinnert ? Von den damaligen Kassenschlagern wie Die Dollarprinzessin, Die Rose von Stambul (Leo Fall), Viktoria und ihr Husar, Die Blume von Hawai (Paul Abraham), Ein Walzertraum (Oscar Straus) etc. gibt es heute weder Aufführungen, noch Partituren noch Klavierauszüge oder CD's. Komponisten, Librettisten und Interpreten sind vergessen. Nur Das weisse Rössl und die grossen Kalmàn-Operetten wie Gräfin Mariza und Die Csardasfürstin werden wieder gespielt, Ersteres von den Berlinern wiederentdeckt, Zweiteres um die österreichischen Seebühnen Mörbisch und Bregenz mit zugkräftigen Werken zu versehen - man kann ja nicht immer nur Lehàr und Robert Stolz spielen, die einzigen Nicht-Juden unter den bekannten Grössen; immerhin emigrierte Robert Stolz, angewidert von den Nazis 1938 nach Frankreich, was ihm 1940 in Paris eine Internierung für «feindliche Ausländer» und eine schwere Lungenentzündung eintrug.

5 Wenn in Österreich Gräfin Mariza, Csardasfürstin und kürzlich auch wieder Die Herzogin von Chicago ${ }^{4}$ auf dem Spielplan stehen, - wer möchte schon daran erinnert werden, dass Kalmàn im März 1938, nachdem SA seine Wohnung besetzt hatte, fluchtartig Wien verlassen musste - und nicht, wie es im Programmheft der Volksoper beschönigend heisst, er habe erkannt, « dass in Wien nicht mehr seines Bleibens (sei) und habe « mit raschem Entschluss » seine Möbel verstaut, "obwohl ihm als Ungar, also Ausländer, unmittelbar keine Gefahr droht $»^{5}$, dass er über die Schweiz und Frankreich nach den USA entkam, wo er 1953 tief deprimiert nach einem Schlaganfall starb. Zugegeben : einer von den « weniger krassen Fällen », Einer, der « nur » Flucht, Verlust seiner Habe, seines Rufes, seiner Existenzgrundlage erlebte! Aber Kalmàn gehörte zu den Berühmten, die vorzugsweise in den USA Aufnahme fanden. Seine Schwestern in 
Ungarn - Vorbild zur Gräfin Mariza - wurden ermordet, sein Neffe überlebte, weil er sich im Massengrab tot stellte und durch die Kadaver herausarbeitete.

Wie erging es nun den anderen, heute weitgehend Vergessenen?

7 Leo Fall, 1873 in Olmütz geboren, Komponist von Die Dollarprinzessin, Die Rose von Stambul, Madame Pompadour, und dem Lied « und der Himmel hängt voller Geigen »... ! hatte das "Glück », schon 1925 in Wien das Zeitliche zu segnen - seine Operetten wurden verboten. Sein Bruder, Richard Fall, ebenfalls Komponist von heute verschollenen Operetten ${ }^{6}$ und dem launigen Schlager "Was machst Du mit dem Knie, lieber Hans»? gelang es zwar, in die USA auszuwandern, er kam aber aus ungeklärten Gründen 1943 nach Frankreich zurück, wurde von der Gestapo gefasst und in Auschwitz ermordet.

Ralph Benatzky, 1884 in Mährisch-Budweis (Österreich-Ungarn) geboren, Schöpfer des Weissen Rössl, und Musik zu über 200 Filmen, - so stammt z.B. von ihm der von Zarah Leander interpretierte Schlager Gebundene Hände aus dem Film Axel an der Himmelstür gelang es, in die USA zu emigrieren, und er starb von tiefen Depressionen heimgesucht 1957 in Zürich. «Wie am wenigsten unangenehm aus dem Leben zu scheiden $»^{7}$, fragt er sich mehrmals in seinen Aufzeichnungen.

9 Auch für Oscar Straus, geboren 1870 in Wien, Komponist unter anderen der Operette Ein Walzertraum, öffneten sich die Tore der Vereinigten Staaten. Einer seiner Söhne beging dort Selbstmord, sein zweiter Sohn wurde 1944 in Theresienstadt umgebracht. Oscar Straus kam nach Österreich zurück und starb 1954 in Ischl.

Paul Abraham, 1892 in Apatin, Ungarn geboren, Komponist der äusserst erfolgreichen Operetten Viktoria und ihr Husar, Die Blume von Hawai, Ball in Savoy, nahm ebenfalls die Emigrationsroute von Frankreich nach den USA. Bei ihm schlugen sich die Schrecken der Vertreibung auf das Gemüt : er wurde wahnsinnig, bedrohte seine besten Freunde mit dem Tode und musste interniert werden. Er starb 1960 in einem Heim in Hamburg. Er gilt unter Kennern als der feinsinnigste der Komponisten, als ein « Richard Strauss, ja sogar ein Strawinsky der Operette $»^{8}$, hiess es $1933 \mathrm{im}$ Wiener Tagblatt von ihm.

11 Bei Leo Ascher, geboren 1880 in Wien, Komponist von den Operetten Vindobona, $d u$ herrliche Stadt, Hoheit tanzt Walzer, und zahlreichen Anderen, erlag 1942, kaum in New York angekommen, einem Schlaganfall. Jene "Zeitbombe " von der Alfred Polgar spricht, die nach den ausgestandenen Strapazen und Schrecken im Herzen tickt und meist früher als später explodiert.

12 Louis Treumann, recte Ludwig Politzer, der1872 in Wien geborene Startenor, bezauberte in der Rolle des Liebhabers in zahllosen Operetten das Publikum, und ist ganz besonders als Danilo in Die lustige Witwe in Erinnerung. Er kam 1943 in Theresienstadt um.

13 Hermann Leopoldi, 1888 in Wien geboren, Publikumsliebling der Wiener, Autor von so «waschechten» Wienerliedern wie In einem kleinen Café in Hernals, Schön ist so ein Ringelspiel, oder I bin a stiller Zecher, Hermann Leopoldi, der eigentlich Hersch Kohn hiess, erlebte Dachau und Buchenwald, kam frei, emigrierte in die USA, und starb 1959 in Wien. Sein Bruder Ferdinand Leopoldi, ebenfalls Musiker, tauchte unter, wurde verraten und ermordet.

Das Schicksal der Textdichter ist meist noch unerfreulicher als das der Musiker.

"Man merkt sich nur die Komponisten, kein Mensch gedenkt der Librettisten ", reimte Julius Brammer, der mit Alfred Grünwald die Texte für zahlreiche Kalmàn- 
Operetten geschrieben hat. Tatsächlich war es für sie, die im Schatten der berühmten Komponisten lebten, nicht immer möglich, nach den USA auszuwandern, und sie sind heute tatsächlich der Vergessenheit anheimgefallen ${ }^{10}$ - ein Grund mehr, an sie zu erinnern.

Bruno Granichstaedten, geboren in Wien 1879, ist der Komponist von der $1925 \mathrm{mit}$ grossem Erfolg gespielten Operette Der Orlow, von ihm stammt die Liedeinlage «Zuschau'n kann'I net » im Weissen Rössl und er hat zahlreiche Textbücher für Oscar Straus-Operetten geschrieben. Er floh über Luxemburg in die USA, wo er sich mühsam als Barpianist durchbrachte und starb verarmt 1944 in New York - sein Wunsch war, in Wien begraben zu sein.

17 Julius Brammer, geboren 1877 in Ungarisch-Brod, verfasste gemeinsam mit Alfred Grünwald die Texte zu vielen Operetten von Emmerich Kalmàn. Er erlag auf der Flucht im April 1943 in Juan les Pins einem Herzinfarkt. Grünwald gelangte nach New York, wo er 1951 starb.

Bela Jenbach, recte Jacobowicz, geboren 1871 in Miskolcz, Österreich-Ungarn, war der Texter für Operetten von Edmund Eysler, dem Autor des Fiakerliedes, Kalmàn (Die Csardasfürstin) und Franz Lehàr (Der Zarewitsch, Paganini). Für Richard Tauber schrieb er die Erfolgsnummer "Gern hab ich die Frau'n geküsst». Er und seine Frau waren in Wien untergetaucht und kamen $1943 \mathrm{um}$.

19 Fritz Löhner-Beda, geboren 1883 in Wildenschwert, Böhmen, war auf der Szene der leichten Muse ein gesuchter Mann. Er schrieb satirische Gedichte, war cabarettistisch tätig, verfasste für Hans Moser Einakterszenen und war vor allem der Texter für die grossen Lehàr- Erfolge wie Das Land des Lächelns, Giuditta, Friederike. Vier Jahre lang litt er in den Konzentrationslagern von Dachau und Buchenwald, bis er 1942 in Auschwitz vergast wurde. «Hat er mich vergessen? » soll er oft in Bezug auf Franz Lehàr gesagt haben.

Ein weiterer Texter Lehàrs, Rudolf Schanzer, beging Selbstmord und Ludwig Herzer, der den Text zu Land des Lächelns verfasst hat, ist in der Emigration umgekommen.

Fritz Grünbaum, geboren 1880 in Brünn, ist der Erfinder der Doppelconférence - mit Karl Farkas. Sein Witz und seine Schlagfertigkeit, den er auf der Bühne des berühmten Wiener Cabarets 'Simpl'glänzen liess, waren stadtbekannt. Er hatte am Ersten Weltkrieg teilgenommen und war mit mehreren Tapferkeitsmedaillen ausgezeichnet worden. Bei den Nazis stand er durch seine offen - und witzig - gezeigte Opposition ganz oben auf der Abschussliste, und es gelang ihm nicht mehr zu entkommen. 1940 erlag er in Dachau den grausamen Folterungen. Seine junge Frau Lily ist seit einer Vorladung bei der Gestapo verschollen.

Auch Karl Farkas, Wiener Publikumsliebling und langjähriger Star des 'Simpl' verdient eine Erwähnung. Ihm gelang eine abenteuerliche Flucht über Spanien und Portugal nach den Staaten, seine beiden Schwestern wurden ermordet: die eine in Theresienstadt, die andere in einem polnischen Lager. Jünger als die vorher Genannten (geb. 1893 in Wien), konnte Farkas aber nach dem Krieg in Wien an seine Karriere wieder anknüpfen. Der Trauerkondukt 1971 für Farkas soll laut Augenzeugen am Zentralfriedhof ungekannte Ausmasse erreicht haben. Farkas war berühmt für seine Reimkunst aus dem Stegreif. Als ihm einmal aus dem Publikum das Wort «Judenbengel » zugerufen wurde, reimte er, indem er eine Rose aus dem Knopfloch nahm : 
Das ist die Rose/Hier ist der Stengel

Ich bin der Jud/Und dort sitzt der Bengel ${ }^{11}$.

Und abschliessend ein Wort über Interpreten :

Das durch Bühne und Film bekannte und beliebte Ehepaar Martha Eggert und Jan Kiepura emigrierte in die Vereinigten Staaten, als 1937 über Kiepura als Halbjude und Regime-Gegner Auftrittsverbot verhängt wurde.

Der gefeierte Operettentenor Richard Tauber ging nach England in die Emigration, wo er 1948 starb. Sein Vater wurde in Buchenwald ermordet.

Opern - und Filmtenor Josef Schmidt, beim Einmarsch der Nazis in Österreich auf der Höhe seines Ruhms, gelang die Flucht in die Schweiz, wo er 1942, nicht vierzigjährig, in einem Internierungslager umkam.

Fakten, die für sich selbst sprechen ! Eine womöglich monotone Reihung, aber das Quantitative muss Zeugnis geben für ein Grauen, das Worte nicht fassen können. Geschicke von Menschen, die damals bekannt, ja sogar berühmt waren, und von deren Leben und Leiden wir noch wissen. Sie stehen für so viele andere, Verschollene, Umgekommene, von denen bestenfalls irgendwo der Name verzeichnet ist. Ob im Rampenlicht oder nur Zuschauer - man möge sie nie vergessen!

\section{NOTES}

1. Die Herzogin von Chicago, Operette von Emmerich Kalmàn, Text von Alfred Grünwald und Julius Brammer.

2. Der Dichter Franz Molnar im Exil, zitiert nach «Sag beim Abschied... Wiener Publikumslieblinge in Bild und Ton", Sammlung Robert Dachs. Ausstellungskatalog der Ausstellung im Museum der Stadt Wien, 1992, S. 149. Zitiert im Weiteren : « Robert Dachs ».

3. Die Wiener Operette, Katalog der 91. Sonderausstellung des Historischen Museums der Stadt Wien, 1984/1985.

4. Wiener Volksoper, Dezember 2004.

5. Wiener Operette, S. 45. Zitiert nach einer Kalman-Biografie von Rudolf Oesterreicher.

6. Das Dameparadies, 1911, Wiener Fratz 1912, z.B.

7. Sammlung Dachs, S. 44.

8. Sammlung Dachs, S.46.

9. Emmerich Kalmàn: Die Herzogin von Chicago, Textbuch der Aufführung in der Wiener Volksoper, Dezember 2004, S. 22.

10. Das Textbuch zur Herzogin von Chicago findet ihr Schicksal keiner Erwähnung wert.

11. Sammlung Dachs, S. 177. 


\section{AUTEUR}

\section{EVA PHILIPPOFF}

Université Charles-de-Gaulle - Lille 3 